\title{
A case-control study of deaths from asthma
}

\author{
HAROLD H REA, ROBERT SCRAGG, RODNEY JACKSON, \\ ROBERT BEAGLEHOLE, JILL FENWICK, DAVID C SUTHERLAND
}

From the Department of Respiratory Medicine, Greenlane Hospital, and the Department of Community Health and General Practice, University of Auckland School of Medicine, Auckland, New Zealand; and Royal Newcastle Hospital, Newcastle, New South Wales, Australia

ABSTRACT A population based case control-study was initiated in 1981 to identify risk factors for death from asthma. Over a two year period all deaths in the Auckland population possibly due to asthma, in people less than 60 years of age, were investigated. From the 47 people who died from asthma 44 who had useful reversibility of airways obstruction (records showing $>20 \%$ variability of peak flow or a history indicating equivalent variability of shortness of breath) before death were selected as cases for the study. Both hospital and community based controls were used. The cases were more likely than were the community controls to have had severe disease, a hospital admission or visits to a hospital emergency department in the previous year (odds ratios 4.4, 16.0, 8.5 respectively). The asthmatic patients who died were more likely than either group of controls to have had a previous life threatening asthma attack. Poor management of the disease and poor compliance on the part of the patient increased the risk of death. In addition, use of three or more types of asthma drug within the past year was associated with an increased risk of dying that was independent of disease severity. Of interest was a similarity between asthmatic patients admitted to hospital and those who died. Nevertheless, a history of a previous life threatening attack and a recent admission to hospital identified a group at high risk.

We report the results of a population based case control study of fatal asthma, which was initiated as part of our investigation into the recent epidemic of deaths from asthma in New Zealand. ${ }^{1}$ The objectives of this study were to describe more fully the patients who die of asthma and to examine the significance of characteristics previously suggested as being associated with death in descriptive studies. ${ }^{2-9}$

\section{Methods}

The cases were all people less than 60 years of age, who had died from 1 January 1981 to 31 December 1982 of asthma that was deemed to have been usefully reversible in the year before death, and who were normally resident in the Auckland region (March 1981 Census population 825958 , about a quarter of the total New Zealand population). Usefully reversible asthma was said to have been present if, in the year before death, there were recordings of swings in peak

Address for reprint requests: Dr H H Rea, Department of Respiratory Medicine, Greenlane Hospital, Auckland, New Zealand.

Accepted 19 May 1986 flow or $\mathrm{FEV}_{1}$ of more than $20 \%$. If this information was not available then a subjective assessment of reversibility from hospital notes, the general practitioner, or a relative was accepted. Forty seven people died from asthma in Auckland over the two years in the age group being studied and $44(94 \%)$ of these were categorised as having had usefully reversible asthma.

Two sets of asthmatic patients were selected as matched controls for those who died. A hospital control patient was randomly selected from all patients discharged from Auckland hospitals after admission for acute asthma. Controls were matched for age $( \pm 5$ years), sex, race, and date of hospital admission. Community controls were identified by asking a random sample of Auckland general practitioners to submit lists of all patients known to have asthma who consulted them over a four week period. This was repeated each quarter so that a control could be found for each patient who died close to the date of death. Like the hospital controls, they were matched for age, sex, and race. All the controls satisfied the definition of "usefully reversible asthma" in the year before their index event. 
For the cases and hospital controls, a detailed questionnaire was administered by one nurse to a close relative or friend, usually a cohabitant of the deceased. The same nurse interviewed the hospital controls themselves and one other nurse interviewer gave the same questionnaire to the community controls. The two nurse interviewers worked closely together, following a detailed instruction manual, and discussed equivocal responses in an attempt to achieve uniformity. Separate questionnaires were administered to any specialist concerned and to the patient's general practitioner. Questionnaires were usually done six to eight weeks after the death, admission, or visit to the general practitioner. The questionnaire covered the nature of the disease, medical management in the last 12 months, and features of the last episode.

Asthma was defined as severe, moderate, or mild. If in the year before entry to the study there had been one or more admissions to hospital or three or more urgent visits to a general practitioner or accident and emergency department, the asthma was classified as severe. The asthma was defined as moderate if the patient had been frequently prevented from working, often woke at night, or needed to visit the doctor urgently because of asthma once or twice in the last year (or any combination of these). A life threatening attack was defined as an attack where consciousness had been disturbed or appreciable hypercapnia had been recorded. Discontinuity of general practice care was defined as failure to attend a general practitioner between acute attacks and visiting several doctors, so that previous records would not be available. Details of the data collection and review methods have been published elsewhere. ${ }^{10}$

To facilitate comparisons of medical care, a scoring system was devised to judge medical management in the previous 12 months. This scoring system was based on accepted criteria for sound medical management, ${ }^{1112}$ and was assessed by calculating a score for each patient from the 12 items shown in table 1 . Some of the items were not applicable or were unanswerable for individual patients, and in that case the question was excluded from the achievable total rather than scored as a "no." Each item was given equal weighting and the optimal score for a particular patient was $100 \%$.

Relative risks were estimated in univariate analyses by use of the matched pairs odds ratio with $95 \%$ confidence limits computed from the binomial distribution. ${ }^{13}$ The proportional hazards model of Cox was used to perform conditional multivariate logistic regression, so that the net relative risk of dying from asthma associated with a particular variable could be estimated after control for confounding variablesfor example, severity. ${ }^{14}$ Differences in proportions were tested by means of the test for independen samples. ${ }^{15}$

\section{Results}

Forty four cases were identified; postmortem result were available for 32 . Matched hospital controls were found for 39 cases and community controls for all cases. Previous hospital records were available for $2 P$ of the cases, 22 of the hospital controls, and 11 of the्छ community controls (table 2a). Hospital notes relating to admissions in other parts of New Zealand and in other countries were not reviewed. For all 34 hospital controls notes pertaining to the index admis $-\overrightarrow{-}$ sion were perused. Few patients in any of the groups were currently attending a hospital clinic (table $3 b)_{\mathrm{\omega}}^{\infty}$ Information for all cases and controls was available from the general practitioner records. This informa tion will have been less reliable for those with discon: tinuity of general practice care (table $3 b$ ). From the various sources we used documented objective eviథ dence for useful reversibility of airways obstructio? was available for 27 cases, 38 hospital controls, an\& 14 community controls.

The mean age of the cases was 33 (range 10-589 years; 25 were male and 19 female. Twenty six of the cases were caucasian, nine Maori and nine Pacifie Islanders.

\section{NATURE OF THE DISEASE}

Characteristics of the patients dying from asthma ar尺

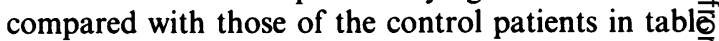
$2 a$ and the relative risk of death associated with these is shown in table $2 b$. More of the cases and hospitar controls than of the community controls had had previous admissions to hospital. The differences weref more striking when we considered only admissions if the previous year. Cases and hospital contro presented to accident and emergency departments if the previous year for the management of severe acute.

Table 1 Scoring of medical management during past 12 months

1 Shown how to use inhaler

2 Used a peak flow meter at home

Substantial agreement between GP and patient about drugs in regular use

4 Continuity of GP care

5 Referred to hospital clinic (only applicable to those with severe asthma)

6 Adequate communication between GP and clinic where applicable

7 Lung function measured by GP in past 12 months

8 Lung function measured by GP at each consultation Evidence that in an unusually bad attack the patient:

9 had been given some advice on what action to take

10 knew he had to increase $\beta$ agonist

11 knew when to start steroids (only applicable to those with severe asthma)

12 knew where to get appropriate help

$\frac{20}{20}$ 
Table 2 Indices of severity and psychosocial problems

(a) Indices of severity in cases and controls

\begin{tabular}{lllc}
\hline & $\begin{array}{l}\text { Cases } \\
(n=44)\end{array}$ & $\begin{array}{l}\text { Hospital controls } \\
(n=39)\end{array}$ & $\begin{array}{l}\text { Community controls } \\
(n=44)\end{array}$ \\
\hline Hospital admission ever (includes past year) & 28 & 22 & 14 \\
Hospital admissions in past year & 17 & 17 & 2 \\
Previous life threatening attack (ever) & 20 & 8 & 0 \\
Previous life threatening attack and admission in past year & 13 & 4 & 2 \\
Accident and emergency department visit in past year & 17 & 13 & 16 \\
Emergency visit to GP in past year & 23 & 21 & - \\
Psychosocial problems noted in hospital or GP records* & 4 & 1 & - \\
Alcoholic & 4 & 2 & - \\
Personality disorder & 4 & 2 & - \\
Depression & 3 & 0 & - \\
Recent bereavement & 3 & 1 & \\
Recent unemployment & 3 & & \\
\hline
\end{tabular}

*Only for cases and hospital controls.

(b) Indices of severity and relative risk* of dying from asthma

\begin{tabular}{|c|c|c|c|c|c|}
\hline \multirow{2}{*}{\multicolumn{2}{|c|}{ Variable }} & \multicolumn{2}{|c|}{$\begin{array}{l}\text { Cases } v \text { hospital controls } \\
(\text { matched pairs }=39)\end{array}$} & \multicolumn{2}{|c|}{$\begin{array}{l}\text { Cases } v \text { community controls } \\
(\text { matched pairs }=44)\end{array}$} \\
\hline & & $\begin{array}{l}\text { Ratio of discordant } \\
\text { pairs }\end{array}$ & $\begin{array}{l}\text { Relative risk } \\
(95 \% C L)\end{array}$ & $\begin{array}{l}\text { Ratio of discordant } \\
\text { pairs }\end{array}$ & $\begin{array}{l}\text { Relative risk } \\
(95 \% C L)\end{array}$ \\
\hline \multirow{7}{*}{\multicolumn{2}{|c|}{$\begin{array}{l}1 \text { One or more hospital admissions for asthma in past year } \\
2 \text { One or more accident and emergency department visits } \\
\text { for asthma in past year } \\
3 \text { Two or more emergency visits to GP for asthma in } \\
\text { past year } \\
4 \text { Severe asthma§ } \\
5 \text { One or more previous respiratory arrests } \\
6 \text { One or more previous life threatening asthma attacks } \\
7 \text { Psychosocial problems }\end{array}$}} & $10 / 12$ & $0 \cdot 8(0 \cdot 3,2 \cdot 1)$ & $16 / 1$ & $\ddagger 16 \cdot 0(2 \cdot 5,665 \cdot 7)$ \\
\hline & & $11 / 10$ & $1 \cdot 1(0 \cdot 4,2 \cdot 9)$ & $17 / 2$ & $\pm 8 \cdot 5(2 \cdot 0,75 \cdot 9)$ \\
\hline & & & & & \\
\hline & & $12 / 10$ & $1 \cdot 2(0 \cdot 5,3 \cdot 1)$ & $22 / 5$ & $+4.4(1.6,14.9)$ \\
\hline & & $5 / 1$ & $5 \cdot 0(0 \cdot 6,237 \cdot 1)$ & $7 / 0$ & $\pm \alpha(1 \cdot 4, \alpha)$ \\
\hline & & $15 / 4$ & $+3.8(1.2,15 \cdot 5)$ & $20 / 0$ & $f \alpha(4.9, \alpha)$ \\
\hline & & $14 / 4$ & $+3.5(1.04,13.7)$ & - & - \\
\hline
\end{tabular}

* Relative risk $=$ ratio of discordant pairs.

tp $<0.05 ; \pm p<0.01$, compared with a relative risk of 1.0 .

$\$ 4$ is derived from 1,2 , and 3 .

CL-confidence limits.

attacks more commonly than did community controls. Seventeen cases had attended accident and emergency departments in the year before death-on an average of five occasions (median 2, range 1-45). Thirteen hospital controls had used accident and emergency departments, with an average of three visits each (median 3, range 1-6), whereas only two of the community controls had presented to accident and emergency departments. There was less difference between cases and controls with regard to the number of urgent visits to a general practitioner in the past year. The 23 cases had on average visited three times (median 3, rage 1-8), the 21 hospital controls $2 \cdot 8$ times (median 3 , range $1-4$ ), and the 16 community controls $2 \cdot 4$ times (median 3, range 1-4).

Table $2 b$ shows that the asthmatic patients who died were more than four times as likely as the community controls to have had severe asthma, 16 times as likely to have had a prior admission to hospital for asthma, and over eight times as likely to have visited a hospital accident and emergency department in the previous 12 months. In contrast, asthmatic patients who died could not be distinguished from the hospital controls by these indicators of the severity of asthma.

Previously reported respiratory arrests or life threatening asthma attacks were significantly more common among asthmatic patients who died than among the community controls. Life threatening attacks were also significantly more common among the cases than among hospital controls.

No significant differences between the cases and either group of controls were found with respect to the age of onset of asthma, family history of asthma, or smoking habits.

Psychosocial problems were more common in cases than in hospital controls (only information from hospital or general practice records was accepted as evidence of psychosocial problems). The relative risk of dying from asthma associated with a psychosocial problem was $3.5(95 \%$ confidence limits $=1.004$, 
Table 3 Aspects of medical management

(a) Medical care and prescription of drugs in mild, moderate and severe asthma

\begin{tabular}{|c|c|c|c|}
\hline & $\begin{array}{l}\text { Cases } \\
(n=42 \dagger)\end{array}$ & $\begin{array}{l}\text { Hospital controls } \\
(n=39)\end{array}$ & $\begin{array}{l}\text { Community controls } \\
(n=44)\end{array}$ \\
\hline $\begin{array}{l}\text { Severe asthma } \\
\text { Number } \\
\text { Medical care score* (mean \%) } \\
\text { Categories of asthma drugs prescribed (mean) }\end{array}$ & $\begin{array}{l}27 \\
49 \\
3 \cdot 5\end{array}$ & $\begin{array}{l}21 \\
58 \\
3 \cdot 8\end{array}$ & $\begin{array}{l}10 \\
62 \\
3 \cdot 4\end{array}$ \\
\hline $\begin{array}{l}\text { Moderate asthma } \\
\text { Number } \\
\text { Medical care score* (mean \%) } \\
\text { Categories of asthma drugs prescribed (mean) }\end{array}$ & $\begin{array}{c}12 \\
48 \\
3 \cdot 1\end{array}$ & $\begin{array}{l}11 \\
58 \\
2 \cdot 5\end{array}$ & $\begin{array}{l}20 \\
65 \\
2 \cdot 8\end{array}$ \\
\hline $\begin{array}{l}\text { Mild asthma } \\
\text { Number } \\
\text { Medical care score* (mean \%) } \\
\text { Categories of asthma drugs prescribed (mean) }\end{array}$ & $\begin{array}{c}3 \\
29 \\
1 \cdot 3\end{array}$ & $\begin{array}{c}7 \\
65 \\
2 \cdot 4\end{array}$ & $\begin{array}{c}14 \\
73 \\
2 \cdot 1\end{array}$ \\
\hline \multicolumn{4}{|l|}{$\begin{array}{l}\text { "See under "Methods." } \\
\text { †Two never attended a general practitioner. }\end{array}$} \\
\hline \multirow[t]{2}{*}{ (b) } & cialist care, $c$ & ompliance & \\
\hline & $\begin{array}{l}\text { Cases } \\
(n=44)\end{array}$ & $\begin{array}{l}\text { Hospital controls } \\
(n=39)\end{array}$ & $\begin{array}{l}\text { Community controls } \\
(n=44)\end{array}$ \\
\hline $\begin{array}{l}\text { Categories of drug prescribed (mean for group as } \\
\text { a whole*) } \\
\text { Discontinuity of GP care } \\
\text { Pulmonary function not measured by GP in last year } \\
\text { Compliance poor as judged by GP } \\
\text { Ever attended a specialist or chest clinic } \\
\text { Currently attending a hospital or chest clinic ( }>2 \text { visits in } \\
\text { past year) }\end{array}$ & $\begin{array}{c}3 \cdot 2 \\
14 \\
29 \\
23 \\
16 \\
7\end{array}$ & $\begin{array}{c}3 \cdot 2 \\
4 \\
19 \\
16 \\
17 \\
\\
6\end{array}$ & $\begin{array}{c}2 \cdot 7 \\
1 \\
15 \\
8 \\
13\end{array}$ \\
\hline
\end{tabular}

(c) Medical management and the relative risk* of dying from asthma

\begin{tabular}{|c|c|c|c|c|}
\hline \multirow[b]{2}{*}{ Variable } & \multicolumn{2}{|c|}{$\begin{array}{l}\text { Cases } v \text { hospital controls } \\
(\text { matched pairs }=39)\end{array}$} & \multicolumn{2}{|c|}{$\begin{array}{l}\text { Cases } v \text { community controls } \\
(\text { matched pairs }=44)\end{array}$} \\
\hline & $\begin{array}{l}\text { Ratio of discordant } \\
\text { pairs }\end{array}$ & $\begin{array}{l}\text { Relative risk } \\
(95 \% \text { CL) }\end{array}$ & $\begin{array}{l}\text { Ratio of discordant } \\
\text { pairs }\end{array}$ & $\begin{array}{l}\text { Relative risk } \\
(95 \% \text { CL) }\end{array}$ \\
\hline $\begin{array}{l}\text { Below average medical care score } \\
\text { Pulmonary function not measured by GP in past year } \\
\text { Three or more categories of asthma drugs prescribed }\end{array}$ & $\begin{array}{l}15 / 8 \\
10 / 9\end{array}$ & $\begin{array}{l}1 \cdot 9(0 \cdot 7,5 \cdot 1) \\
1 \cdot 1(0 \cdot 4,3 \cdot 1)\end{array}$ & $\begin{array}{l}20 / 7 \\
19 / 7\end{array}$ & $\begin{array}{l}\dagger 2 \cdot 9(1 \cdot 2,8 \cdot 0) \\
\dagger 2 \cdot 7(1 \cdot 1,7 \cdot 6)\end{array}$ \\
\hline $\begin{array}{l}\text { by doctor in past year } \\
\text { Three or more categories of asthma drugs taken by patient }\end{array}$ & $12 / 7$ & $1 \cdot 7(0 \cdot 6,5 \cdot 1)$ & $15 / 5$ & $+3.0(1.04,10.5)$ \\
\hline $\begin{array}{l}\text { in last year } \\
\text { Patients' non-compliant with medical treatment }\end{array}$ & $\begin{array}{l}13 / 13 \\
13 / 9\end{array}$ & $\begin{array}{l}1 \cdot 0(0 \cdot 4,2 \cdot 3) \\
1 \cdot 4(0 \cdot 6,3 \cdot 8)\end{array}$ & $\begin{array}{l}17 / 7 \\
21 / 0\end{array}$ & $\begin{array}{l}2 \cdot 4(0 \cdot 96,6 \cdot 9) \\
\pm \alpha(5 \cdot 2, \alpha)\end{array}$ \\
\hline
\end{tabular}

${ }^{*}$ Relative risk $=$ ratio of discordant pairs
$t \mathrm{p}<0.05 ; \neq \mathrm{p}<0.01$, compared with a relative risk of 1.0 .
$\mathrm{CL}-$ confidence limits.

13.7) when cases were compared with hospital controls. Psychosocial variables were not examined in community controls. Among cases and hospital controls psychosocial problems did not appear to be more common in any particular racial group, affecting 16 Europeans, four Pacific Islanders and three Maoris.
MEDICAL MANAGEMENT IN THE PAST 12 MONTHS Tables $3 a$ and $3 b$ show aspects of medical manage ment and table $3 c$ the relative risks of dying frorep asthma associated with these. In table $3 a$ medical care scores are shown with the patients stratified accordin $\bar{g}$

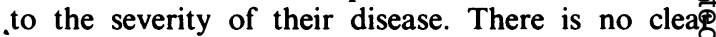
relationship between medical care scores and severit 
but for all grades of severity those who died appear to have received poorer medical care than either group of controls-that is, they had lower medical care scores. Two of the cases had never sought routine general practice care; instead they used accident and emergency departments or emergency general practice services during attacks. Below average scores (that is, below the average for all cases and controls combined) were estimated to be three times as frequent in those who died than in community controls and twice as common as in hospital controls (table $3 c$ ). This increase was significant when cases were compared with community controls, and was independent of the degree of asthma severity. One component of the medical care score-failure by the general practitioner to measure pulmonary function within the last year-was associated with about a threefold increase risk of dying from asthma when cases were compared with community controls (table $3 c$ ). Multivariate analyses showed that this was independent of asthma severity.

The role of multiple medication was investigated. Asthma drugs were classified into five categories: $\beta$ agonists, theophyllines, sodium cromoglycate, inhaled corticosteroids, and oral corticosteroids. The information was obtained from two sources: from the general practitioner for drugs prescribed and from a patient or relative for the drugs taken. The mean number of categories of asthma drugs prescribed is shown for the cases and controls stratified for severity of disease and for the groups as a whole in tables $3 \mathrm{a}$ and $3 \mathrm{~b}$. Patients with mild asthina were prescribed fewer drugs but the mean number of drugs prescribed for the groups as a whole did not differ greatly. The use of three or more categories of asthma drugs within the past years was, however, associated with an increased risk of dying from asthma when cases were compared with community controls (table $3 c$ ), regardless of the source of information. This relationship was also independent of severity of asthma. Non-compliance by patients with medical treatment was determined from the opinion of the patient, relative, or doctor (only the general -practitioner's judgment is shown in table $3 b$ ) or from hospital notes, or both. Admittedly, non-compliance was difficult to assess but it appeared to be associated with an increased risk of dying from asthma. This was particularly so for comparisons between cases and community controls, and multivariate analyses showed that this result was independent of asthma severity (table $3 c$ ). Discontinuity of general practice care was also more common in cases than in controls.

\section{Discussion}

This study, apparently the first study of asthma mor- tality to include control groups, has identified several factors that delineate patients with asthma who are at high risk of death and allows confidence limits to be applied to these risk factors. The study confirms earlier findings that a recent hospital admission, recent visits to an accident and emergency department, a previous respiratory arrest or life threatening attack, poor medical management, and poor compliance are significant risk factors for death from asthma. ${ }^{2-9}$ In addition, the similarity between cases and hospital controls is in accord with the common experience that patients admitted to hospital have more troublesome asthma than those with no previous admissions. Indeed, the best way to identify asthmatic patients at risk of death is to identify those who have had a recent hospital admission and in particular those who have ever had a life threatening attack.

Asthmatic patients who are admitted to hospital and those who die appear to come from a similar portion of the asthmatic population-that is, they have troublesome disease (admissions to hospital), are non-compliant, and use accident and emergency departments for treatment of acute attacks. There is, however, a suggestion of some dissimilarities between those who die and the hospital controls. Those who die may have had more severe disease (previous life threatening attacks), received poorer medical care, had more discontinuous general practice care, and had more psychosocial problems. The importance of some of these factors was, however, hard to judge. The assessment of psychosocial problems was made only from general practice records and hospital notes. The latter were infrequently available for community controls so psychosocial data are not shown for this group. Furthermore, community controls were selected by their attendance at a general practice, so judgment about continuity of care may be biased. Medical care appeared to have been better for hospital controls than for cases but the relative risk estimate did not reach significance. Medical care scores were better for community controls than for either cases or hospital controls. Clearly attitudes of patient and family to compliance and the need for continuous general practice care would influence medical care scores. Non-compliance was difficult to assess since it could not always be judged from already documented sources.

The major strength of this study is that it is population based, and thus avoids the selection biases that may occur in hospital based studies. By comparison with controls it also allows confidence limits to be applied to previously described risk factors. The cases included all asthma deaths in people with reversible asthma aged less than 60 years occurring in Auckland during 1981-2 and represented $94 \%$ of all those who died from asthma. Within the constraints of the 
matching variables (age, sex, race, date of death), the controls were representative of their respective hospital or general practitioner treated asthma populations since they were randomly selected from all asthmatic patients admitted to hospital with acute asthma and those treated by all general practitioners within Auckland during 1981-2.

It is possible that misclassification biasesspecifically recall, interviewer, and reviewer biasesare present in this study. Recall bias could have been introduced since some of the basic information about cases came from relatives whereas for controls the corresponding information came from the patients themselves. For example, the reviewers found that more of the items listed in table 1 lacked an answer for the cases than for the controls because of vague or indeterminate answers from the relatives. But by excluding such items in the scoring of medical management the bias would tend to favour the cases - that is, where a relative answered "Don't know" the question was excluded even though the correct answer may have been "No." For the first 10 controls recruited, answers from relatives and the patients themselves were compared. For hospital admissions, previous life threatening attacks, urgent medical care, and estimates of compliance concordance was excellent.

Interviewer and reviewer bias was harder to deal with. It was not possible to "blind" the reviewers on whether they were assessing a patient who died or a control. An attempt was made to look for such bias by having an independent reviewer assess many of the cases. Concordance was extremely high between this independent reviewer and the Auckland reviewers.

Misclassification bias is less likely where recorded information was available and for many of the assessments hospital notes or general practitioners' records were the source. Most of the comparisons presented in this paper are based on recorded information. More subjective features such as the circumstances surrounding the death were not investigated as they do not lend themselves easily to a comparison of patients who died with the controls because of the major potential for recall bias.

It was unfortunately not possible to judge accurately whether oral theophylline or the use of nebulisers, which have been implicated as possible reasons for the increased asthma mortality rates in New Zealand, ${ }^{1617}$ were associated with an increased risk of death. Although there was no anecdotal evidence for an excessive use of drugs immediately before death, nebulisers, for example, were used by so few patients that the power of this study to identify increased risks was very low. It was also difficult to determine whether cases or controls were currently taking oral theophylline. For both the cases and the controls recall about drugs might well have been biased. The information came from relatives of the cases but $\mathrm{di}-\overrightarrow{\vec{F}}$ rectly from the controls, often many weeks after the event under study. Medical records of the drugs given were often incomplete and differed considerably from $\overline{\frac{5}{5}}$ the information obtained from patients and $\overrightarrow{\widetilde{\sigma}}$ relatives - particularly so for the various drug groups other than $\beta$ agonists, These doubts about the validityos of the information on drugs in this study indicate the $\overrightarrow{-}$ need for further and more specific studies of theirpossible role in asthma deaths.

There is some evidence from the study that factors? in the asthmatic patient's life style may be associated? with an increased risk of death from asthma. For ex- $₫$ ample, the cases were found to be less compliant thanthe community controls. Because of the partly subjec-io tive nature of this measurement, however, we cannotew be certain about the importance of this. Cases wereo more likely to have prior psychosocial problems thanhospital controls.

The findings from this study are compatible with? the hypothesis that some of those who die may be 3 confused about how and when to use their various asthma medications. The prescription of three or more categories of asthma drugs was associated with ${ }_{\infty}^{\oplus}$ an increased relative risk of death that was indepen- - . dent of asthma severity. Disagreement between the patient and the usual doctor about drug usage wass more common in those who died than in community controls. This is unlikely to be related to the numbero of drugs taken by subjects as there was little difference in the number of drugs prescribed for cases and con $-\overrightarrow{\vec{P}}$ trols (table $3 b$ ). These risk factors may be further con-응 founded by non-compliance and by psychosocial problems. Such confusion may partly explain why in a large proportion of the recent deaths from asthma in New Zealand medical advice had not been soughto during the final asthma attack. ${ }^{10}$

We have identified several risk factors for deatho from asthma in this study that are important for the clinician. The results show that asthmatic patientso who have had a recent admission to hospital, a recent? visit to an emergency department, or a previous lifeo threatening asthma attack are at increased risk of dying from asthma.

That patients with these risk factors require specia medical attention is emphasised by the finding of ano increased risk of dying from asthma associated with an below average medical care score. Over $60 \%$ of thosen who died in this study had had previous hospital ad- - missions because of asthma and could have been selected for special care and follow up at least by their? general practitioners. Hospital follow up, in addition, 0 could be offered to asthmatic patients who have had a recent hospital admission plus a previous life threat $-\overline{0}$ ening attack, especially if there is evidence of poor management in general practice or poor use of gen $\frac{?}{\mathrm{D}}$ 
eral practice care. This might have helped the $30 \%$ of patients in this study who could have been identified in this way before their death.

This study was funded by the Auckland Asthma Society, the Maurice and Phyllis Paykel Trust, and the Medical Research Council of New Zealand. RJ was a Medical Research Council of New Zealand training fellow in epidemiology. We thank Elaine Bollard and Eva Hochstein for their help with the data collection.

\section{References}

I Jackson RT, Beaglehole R, Rea HH, Sutherland DF. Mortality from asthma: a new epidemic in New Zealand. Br Med J 1982;285:771-4.

2 Anonymous. Fatal asthma [editorial]. Lancet 1979;ii:337-8.

3 Johnson AJ, Nunn AJ, Somner AR, Stableforth DE, Stewert CJ. Circumstances of deaths from asthma. $\mathrm{Br}$ Med J 1984;288:1870-2.

4 Cochrane GM, Clark TJH. A survey of asthma mortality in patients between ages 35 and 64 in the Greater London hospitals in 1971. Thorax 1975;30:300-5.

5 Macdonald JB, Seaton A, Williams DA. Asthma deaths in Cardiff in 1963-74: 90 deaths outside hospital. $\mathrm{Br}$ Med J 1976;i:1493-5.

6 Macdonald JB, Macdonald ET, Seaton A, Williams DA. Asthma deaths in Cardiff 1963-74: 53 deaths in hospital. Br Med J 1976;ii:721-3.
7 Omerod LP, Stableforth DE. Asthma mortality in Birmingham 1975-7: 53 deaths. $\mathrm{Br}$ Med J 1980;280:687-90.

8 Hetzel MR, Clark TJH, Branthwaite MA. Asthma: analysis of sudden deaths and ventilatory arrests in hospital. Br Med J 1977;i:808-11.

9 Fraser PM, Speizer FE, Waters SDM, Doll R, Mann NM. The circumstances preceding death from asthma in young people in 1968 to $1969 . \mathrm{Br} J$ Dis Chest 1971;65:71-84.

10 Sutherland DC, Beaglehole R, Fenwick J, Jackson RT, Mullins P, Rea HH. Death from asthma in Auckland: circumstances and validation of causes. NZ Med J 1984;97:845-8.

11 Hetzel MR, Clark TJH. Management of adult asthma. In: Clark TJH, Godfrey S, eds. Asthma. London: Chapman and Hall, 1983:457-84.

12 Paterson JW, Tarala RA. Asthma: common pitfalls in management. New Ethicals 1981;18:39-48.

13 Breslow NE, Day NE. Statistical methods in cancer research. Vol 1: The analysis of case-control studies. Lyon: International Agency for Research in Cancer, 1980. IARC Scientific Publications, No 32.

14 Harrell FE. The PHGLM procedure. In: Sugi Supplemental Library Users Guide. North Carolina. SAS Institute Inc, 1983:267-94.

15 Colton T. Statistics in medicine. Boston, Mass: Little, Brown, 1974.

16 Wilson JD, Sutherland DC, Thomas AC. Has the change to beta-agonists combined with oral theophylline increased cases of fatal asthma? Lancet 1981;i:1235-7.

17 Grant IWB. Asthma in New Zealand. Br Med J 1983;286:374-7. 